\title{
Dihydrotestosterone in Prostatic Hypertrophy
}

\section{THE FORMATION AND CONTENT OF DIHYDROTESTOSTERONE IN THE HYPERTROPHIC PROSTATE OF MAN}

\author{
Pentti K. Sirteri and Jean D. Wirson with the technical assistance of \\ Jo ANN MaYfietd \\ From the Departments of Obstetrics and Gynecology, Biochemistry, and \\ Internal Medicine, The University of Texas Southwestern Medical School \\ at Dallas, Dallas, Texas 75235
}

\begin{abstract}
A B S T R A C T To explore the relation between androgens and prostatic hypertrophy in man, the concentrations of testosterone, dihydrotestosterone, and androstenedione and the rate of conversion of testosterone to dihydrotestosterone have been measured in normal and hypertrophic prostate tissue. First, a double isotope derivative technique was adapted for the measurement of tissue androgen content in 15 normal and 10 hypertrophic prostates. Although there was no significant difference in the content of androstenedione and testosterone between the two types of tissue, the content of dihydrotestosterone was significantly greater in the hypertrophic tissue $(0.60 \pm 0.10 \mu \mathrm{g} / 100 \mathrm{~g})$ than in the normal glands $(0.13 \pm 0.05 \mu \mathrm{g} / 100 \mathrm{~g})$. Second, a regional study was performed in three normal prostates and four glands with early hypertrophy, and it was demonstrated that the dihydrotestosterone content was two and three fold greater in the periurethral area where prostatic hypertrophy usually commences than in the outer regions of the gland. Finally, the rate of conversion of testosterone to dihydrotestosterone has been measured under standardized conditions in tissue slices from 4 normal and 20 hypertrophic prostates. There was no significant difference in the rate of dihydrotestosterone formation between the two types of gland $(6.0 \pm 0.8$ and $7.8 \pm 0.5$ $\mu \mu$ moles $/ 15 \mathrm{mg}$ of tissue per $\mathrm{hr}$ ). While the mechanism by which dihydrotestosterone accumulation occurs remains unexplained, it is possible that the local accumu-
\end{abstract}

This work was presented in part at the meeting of the Endocrine Society in 1970 and has been published in abstract form (1).

Dr. Wilson is the recipient of a Career Development Award of the U. S. Public Health Service (AM 25989).

Received for publication 6 March 1970 and in revised form 12 May 1970. lation of dihydrotestosterone may be involved in the pathogenesis of prostatic hypertrophy in man.

\section{INTRODUCTION}

The development of benign prostatic hypertrophy is an almost universal phenomenon in aging men. The natural history and clinical features of this condition have been the subject of a considerable amount of study (2-7), and it is now possible to make a number of generalizations about its development. The prostate gland weighs only a few grams at birth; at the time of puberty it undergoes androgen-induced growth and reaches the adult size of approximately $20 \mathrm{~g}$ by about $20 \mathrm{yr}$ of age. The gland remains stable, both in regard to weight and histological characteristics, for approximately $25 \mathrm{yr}$. Then, commencing in the 5th decade a second growth spurt occurs in approximately $75 \%$ of men $(8,9)$. This second growth phase, unlike the earlier growth which involves the whole gland diffusely, begins characteristically in the periurethral regions as a localized proliferation involving fibronodular and glandular elements (10). While this hyperplastic process may remain limited in scope and not result in significant enlargement of the gland, in many individuals the hyperplasia progresses to compress the remaining gland and eventually may not only cause the prostate to reach enormous size but may produce urinary tract obstruction and constipation as well $(2,3,5,6)$.

There is considerable evidence that the second spurt, like the growth of the prostate during puberty, requires a functioning testis (4), and the concept has been advanced by several investigators that some form of endocrine imbalance in the aging male might be 
causal in this process $(4,7)$. However, to date no form of hormone treatment, either with androgens (4) or estrogens $(4,11,12)$, has produced a convincing prostatic hypertrophy in experimental animals, and, furthermore, neither castration in man (13) nor drug therapy that results in diminished testosterone ${ }^{1}$ secretion or that impedes its peripheral action $(14,15)$ result in uniformly beneficial effects after the prostate has already hypertrophied.

Several recent developments in concepts of testosterone action in target tissues make it pertinent to reexplore the possibility of a role of certain androgens in the pathogenesis of benign prostatic hypertrophy. First, in the prostate of man (16-21) as well as in the prostates of many animal species $(16,18,21,22)$ the major metabolite of testosterone has been shown to be its $5 \alpha$ reduced derivative dihydrotestosterone. Second, after the administration of testosterone $-{ }^{3} \mathrm{H}$ to rats, dihydrotestosterone is the principal radioactive steroid bound to the prostatic nuclear chromatin, a presumed site of action of the hormone (23). Third, in 11 animal species the rate of conversion of testosterone to dihydrotestosterone by prostate slices correlates with the ultimate size of the gland (21). Finally, the administration of dihydrotestosterone results in prostatic growth both in organ cultures of rat prostate $(24,25)$ and in long and short term in vivo studies in both the rat (26-29) and dog (30).

Together, these lines of evidence suggest that the conversion of testosterone to dihydrotestosterone by the prostate may possibly be involved in the pathogenesis of prostatic hypertrophy. The present study was designed to determine the concentrations of testosterone and dihydrotestosterone in normal and hypertrophic human prostate and to measure the rates of conversion of testosterone to dihydrotestosterone in the two types of prostate.

\section{METHODS}

Analysis of content of steroids in tissues. The technique utilized for the tissue analysis of steroid content is a modification of a double isotope derivative assay which has been described previously for the analysis of progestins and androgens in blood $(31,32)$. Two types of tissues were utilized for this study, prostate glands removed at surgery from men undergoing suprapubic or retropubic prostatectomy for benign prostatic hypertrophy and prostate glands removed at autopsy. The autopsy samples were all obtained from medicolegal autopsies of accident victims; the bodies were brought to the morgue and refrigerated within $4 \mathrm{hr}$ of

1 The following abbreviations are used: testosterone, $17 \beta$ hydroxyandrost-4-en-3-one; dihydrotestosterone, $17 \beta$-hydroxy-5 $\alpha$-androstan-3-one; androstenedione, androst-4-ene3,17 -dione; androstandione; $5 \alpha$-androstane-3,17-dione; dehydroepiandrosterone, $3 \beta$-hydroxyandrost-5-en-17-one; 19 -nortestosterone, $17 \beta$-hydroxyestr-4-en-3-one; androstandiol, $5 \alpha$ androstane- $3 \alpha, 17 \beta$-diol and $5 \alpha$-androstane- $3 \beta, 17 \beta$-diol. death. An average of $11.5 \mathrm{hr}$ elapsed between the time of death and the time of removal of the prostate glands.

The prostate glands were dissected free of extraneous connective tissue and then frozen. After 6-12 samples were accumulated, individual samples were allowed to thaw, and $10-25 \mathrm{~g}$ portions were minced with scissors and placed in a Virtis Model 23 homogenizing vessel (The Virtis Co., Inc., Gardiner, N. Y.) which was kept on ice. $50 \mathrm{ml}$ of cold methanol was added to each homogenizing vessel followed by the addition of approximately $3200 \mathrm{dpm}$ each of ${ }^{14} \mathrm{C}-\mathrm{la}-$ beled indicator steroids. The tissue samples were homogenized for 5 min during which time the temperature was maintained at about $5^{\circ} \mathrm{C}$. The homogenates were centrifuged at $7000 \mathrm{rpm}$ for $30 \mathrm{~min}$ in the cold, and the supernatant fluid was decanted. The residue was resuspended in a similar volume of cold methanol and allowed to stand overnight at $3^{\circ} \mathrm{C}$. The samples were again centrifuged, and the two supernatants were combined. The volume of the methanol extract was reduced to $60 \mathrm{ml}$ after which $26-28 \mathrm{ml}$ of distilled water was added to each sample. The aqueous mixture was transferred to a separatory funnel and was extracted first with $100 \mathrm{ml}$ and then with $50 \mathrm{ml}$ of $n$-hexane. The hexane extracts were discarded, and the methanol-water phase was reduced in volume until only water remained. Steroids were removed from the latter by three extractions with $50 \mathrm{ml}$ of redistilled ether. The individual ether extracts were combined and evaporated to dryness in a stream of dry nitrogen. The residue from each tissue sample was dissolved in benzene: hexane $(1: 1)$ and then passed through a column $(0.7 \times 12 \mathrm{~cm})$ of basic alumina containing $3 \%$ water. The column was washed with an additional $10 \mathrm{ml}$ of benzene: hexane, and the washings were discarded. The steroid fraction was eluted with $30 \mathrm{ml}$ of the same solvent mixture containing $1 \%$ ethanol. The solution of eluted steroids was transferred to a small screw cap test tube and thoroughly dried in a vacuum oven at $50^{\circ} \mathrm{C}$ overnight. Each sample was then labeled with tritium by enol-exchange with alumina- ${ }^{3} \mathrm{H}_{2} \mathrm{O}$ as previously described $(31,32)$.

After exchange labeling, carrier steroids were added to each sample, and the dually labeled mixture was subjected to gradient elution chromatography on Celite using essentially the same procedure as described earlier (32). After assay of the tubes for radioactivity, the appropriate zones for each steroid were combined, and each individual steroid was subjected to three successive thin-layer chromatographic purifications in the following systems: chloroform: ethyl acetate $(13: 1)$, ether: methylene chloride $(9: 1)$, and ethyl acetate: isooctane $(7: 3)$. Each of the steroids was then subjected to acetylation with pyridine: acetic anhydride $(1: 1)$ overnight at room temperature. The steroid acetates and reclaimed androstenedione were further purified by thin-layer chromatography using isooctane: ethyl acetate $(6: 4) .{ }^{3} \mathrm{H}$ to ${ }^{14} \mathrm{C}$ isotope ratios were determined on aliquots after the third and fourth thin-layer chromatographic steps in order to ascertain constancy of isotope ratios. In addition to the use of simultaneously treated androgen $-{ }^{14} \mathrm{C}$ standards, 19-nortestosterone $-{ }^{14} \mathrm{C}$ was added to each tissue sample and treated as a standard. Since this compound has not been reported to be present in prostatic tissue or in blood, the 19-nor-testosterone served as an internal standard for the detection of any loss in efficiency of labeling as compared with the independent standards. The amount of endogenous steroid was calculated from the final ${ }^{3} \mathrm{H}$ to ${ }^{14} \mathrm{C}$ ratio of each steroid and the effective specific activity of the $\mathrm{Al}_{2} \mathrm{O}_{3}{ }^{3} \mathrm{H}_{2} \mathrm{O}$ as determined from the simultaneously run standards. Water blanks were run with each set of samples, and representative 
TABLE I

Recovery of Testosierone, Dihydrotestosterone, Androstenedione, and Dehydroepiandrosterone from Tissues under Varying Conditions

\begin{tabular}{|c|c|c|c|c|c|c|}
\hline \multirow[b]{2}{*}{ Exp. } & \multirow[b]{2}{*}{ Sample } & \multirow[b]{2}{*}{ Treatment } & \multicolumn{4}{|c|}{ Hormone content } \\
\hline & & & Testosterone & Dihydrotestosterone & Androstenedione & Dehydroepiandrosterone \\
\hline & & & & & $\mu g / 100 \mathrm{~g}$ & \\
\hline \multirow[t]{2}{*}{1} & Hypertrophic & Saline extraction & 0.12 & 0.34 & 0.04 & 0.13 \\
\hline & Prostate & Methanol extraction & 0.18 & 0.35 & 0.03 & 0.14 \\
\hline \multirow[t]{2}{*}{2} & Hypertrophic & Frozen immediately & 0.05 & 0.46 & 0.15 & 0.66 \\
\hline & Prostate & $\begin{array}{l}\text { Allowed to sit } 4 \mathrm{hr} \text { at } \\
\text { room temperature } \\
\text { and } 8 \mathrm{hr} \text { at } 5^{\circ} \mathrm{C}\end{array}$ & 0.06 & 0.47 & 0.04 & 0.50 \\
\hline \multirow[t]{2}{*}{3} & Psoas muscle & $\begin{array}{l}\text { Autopsy samples ob- } \\
\text { tained from an in- } \\
\text { dividual castrated } \\
\text { because of prostatic } \\
\text { carcinoma }\end{array}$ & 0.01 & 0.01 & 0.02 & 0.11 \\
\hline & Prostate & & 0.01 & 0.04 & 0.05 & 0.21 \\
\hline
\end{tabular}

water and tissue blanks are shown in Tables I and II. In view of the low values obtained both for water and tissue blanks, these values were not subtracted from the data presented in this paper; and in all but three instances the tissue values were significantly higher than the blank values.

The accuracy and precision of this method are illustrated in Tables I and II. First, two techniques were compared for the initial homogenization of the tissue, and similar results were obtained (experiment 1, Table I). Then, the steroid content of prostate obtained at surgery and frozen immediately was compared with results obtained from an aliquot of the same gland which was kept at room temperature for $4 \mathrm{hr}$ and at $5^{\circ} \mathrm{C}$ for $8 \mathrm{hr}$ before freezing. Again, similar results were obtained for the four steroids measured (experiment 2, Table I). Then, steroid content was measured in psoas muscle and prostate from an individual castrated because of metastatic carcinoma of the prostate (experiment 3 , Table II). It is of interest that the androgens derived ultimately from the testis (testosterone and dihydrotestosterone) were exceedingly low in psoas muscle and prostate from the castrated man, whereas the levels of two adrenal androgens (androstenedione and dehydroepiandrosterone) were the same in these tissues as in the hypertrophic prostates. Finally, representative steroid recoveries and water blanks are listed in Table II. Recoveries averaged $87 \%$ for the three androgens. As the result of these studies it has been concluded that in regard to accuracy and sensitivity, the previously described double isotope derivative technique for the measurement of circulating steroids is applicable for the measurement of these tissue androgens.

Dihydrotestosterone formation by tissue slices. A previously described method for the measurement of dihydrotestosterone formation by prostate slices was miniaturized for use in these studies (21). Two types of tissues were used, surgical specimens obtained from men undergoing suprapubic or retropubic prostatectomy and needle biopsy samples obtained at surgery from individuals with a variety of suspected lesions; the needle biopsy samples used for this study all proved to be normal histologically. Immediately after removal, the tissues were placed in chilled saline and taken to the laboratory in an ice bucket. In the case of the hyper- trophic prostates, tissue slices, approximately $0.5 \mathrm{~mm}$ in thickness, were prepared by hand. The biopsy samples of normal prostate glands and the tissue slices from the hypertrophic prostates were blotted, weighed, and added to tubes containing the incubation mixture.

The standard incubation mixture consisted of prostate slices $(15 \mathrm{mg})$, testosterone-1,2- ${ }^{8} \mathrm{H}\left(3.5 \times 10^{-8} \mathrm{M}\right.$ containing $\left.5 \times 10^{\circ} \mathrm{cpm}\right)$, glucose $\left(1.1 \times 10^{-2} \mathrm{M}\right)$, and Krebs-Ringer phosphate buffer, $\mathrm{pH} 7.4$ in a total volume of $2.5 \mathrm{ml}$. The tubes were gassed with $95 \% \mathrm{O}_{2}-5 \% \mathrm{CO}_{2}$, capped, and incubated at $37^{\circ} \mathrm{C}$ with shaking for $1 \mathrm{hr}$. In most instances, less than 30 min elapsed between the time of removal of the tissues and the beginning of the incubation.

At the end of the incubation period, the reaction was stopped by the addition of $10 \mathrm{ml}$ of chloroform:methanol (2:1), and the lipids were extracted and backwashed as described by Folch, Lees, and Sloane Stanley (33). An aliquot of the washed chloroform: methanol extract was taken to dryness and chromatographed along with a mixture of steroid standards by thin-layer chromatography utilizing the chloroform: methanol $(99: 1)$ system of Gomez and Hsia (34). The steroids were recovered from the plates and analyzed for radioactivity as previously described (35).

TABLE II

Recovery of Testosterone, Dihydrotestosterone, and Androstenedione

\begin{tabular}{lcccc}
\hline & \multirow{2}{*}{$\begin{array}{c}\text { Water } \\
\text { blank* }\end{array}$} & \multicolumn{3}{c}{ Hormone } \\
\cline { 3 - 5 } \cline { 4 - 5 } & & Added & \multicolumn{2}{c}{ Recovered $\ddagger$} \\
\hline Testosterone & 0.0008 & 0.0205 & 0.0165 & 80 \\
Dihydrotestosterone & 0.0016 & 0.0228 & 0.0196 & 86 \\
Androstenedione & 0.0002 & 0.0174 & 0.0183 & 106 \\
\hline
\end{tabular}

* Mean values obtained from eight separate a nalyses of each steroid.

$\ddagger$ Before calculation of the recovery, the water blank was subtracted.

Dihydrotestosterone in Human Prostate 
TABLE III

The Content of Testosterone, Dihydroteslosterone, and Androstenedione in Normal and Hypertrophic Prostate Glands

\begin{tabular}{|c|c|c|c|c|c|}
\hline \multirow[b]{2}{*}{ Exp. No. } & \multirow{2}{*}{$\begin{array}{l}\text { Age of } \\
\text { patient }\end{array}$} & \multirow{2}{*}{$\begin{array}{l}\text { Weight of } \\
\text { prostate }\end{array}$} & \multicolumn{3}{|c|}{ Hormone content } \\
\hline & & & Testosterone & Dihydrotestosterone & Androstenedione \\
\hline & $y r$ & $g$ & & $\mu g / 100 \mathrm{~g}$ & \\
\hline \multicolumn{6}{|l|}{ Normal prostate } \\
\hline 1 & 45 & 20 & 0.15 & 0.12 & 0.01 \\
\hline 2 & 15 & 5 & 0.46 & 0.12 & 0.08 \\
\hline 3 & 22 & 11 & 0.09 & 0.12 & 0.09 \\
\hline 4 & 19 & 8 & 0.05 & 0.19 & 0.06 \\
\hline 5 & 22 & 22 & 0.05 & 0.06 & 0.14 \\
\hline 6 & 28 & 22 & 0.04 & 0.18 & 0.65 \\
\hline 7 & 32 & 19 & 0.03 & 0.05 & 0.03 \\
\hline 8 & 42 & 34 & 0.08 & 0.14 & 0.07 \\
\hline 9 & 18 & 16 & 0.01 & 0.06 & 0.03 \\
\hline 10 & 43 & 17 & 0.03 & 0.03 & 0.10 \\
\hline 11 & 36 & 16 & 0.06 & 0.08 & 0.04 \\
\hline 12 & 66 & 22 & 0.03 & 0.04 & 0.02 \\
\hline 13 & 27 & 18 & 0.18 & 0.07 & 0.05 \\
\hline 14 & 22 & 17 & 0.15 & 0.06 & 0.02 \\
\hline 15 & 57 & 24 & 0.13 & 0.17 & 0.02 \\
\hline Mean \pm SEM & $33 \pm 4$ & $18 \pm 2$ & $0.09 \pm 0.03$ & $0.13 \pm 0.05$ & $0.09 \pm 0.04$ \\
\hline \multicolumn{6}{|l|}{ Hypertrophic prostate } \\
\hline 16 & 94 & 30 & 0.15 & 0.97 & 0.03 \\
\hline 17 & 72 & 24 & 0.17 & 0.34 & 0.05 \\
\hline 18 & 77 & 45 & 0.06 & 1.19 & 0.04 \\
\hline 19 & 75 & 56 & 0.13 & 0.45 & 0.05 \\
\hline 20 & 74 & 124 & 0.04 & 0.61 & 0.03 \\
\hline 21 & 81 & 17 & 0.03 & 0.19 & 0.02 \\
\hline 22 & 64 & 11 & 0.06 & 0.47 & 0.04 \\
\hline 23 & 69 & 69 & 0.01 & 0.37 & 0.03 \\
\hline 24 & 70 & 45 & 0.20 & 0.60 & 0.04 \\
\hline 25 & 73 & 40 & 0.03 & 0.82 & 0.04 \\
\hline Mean \pm SEM & $75 \pm 3$ & $46 \pm 10$ & $0.09 \pm 0.02$ & $0.60 \pm 0.10$ & $0.04 \pm 0.03$ \\
\hline
\end{tabular}

\section{RESULTS}

The androgen content of the human prostate. The results of measurements of the concentrations of testosterone, dihydrotestosterone, and androstenedione in 15 normal prostate glands obtained at autopsy and in 10 hypertrophic prostate glands removed at surgery are listed in Table III. The average age of the subjects was 33 for the normal group and 75 for the group with benign prostatic hypertrophy. The average prostate weight was $18 \mathrm{~g}$ for the normal group and $46 \mathrm{~g}$ for the hypertrophic glands, figures almost identical to those published by Swyer (9). There was no significant difference in the average concentration of testosterone $(0.09 \pm$ SEM 0.03 and $0.09 \pm$ SEM $0.02 \mu \mathrm{g} / 100 \mathrm{~g}$ ) or of androstenedione $(0.09 \pm$ SEM 0.04 and $0.04 \pm 0.03 \mu \mathrm{g} / 100 \mathrm{~g})$ between the two groups of glands. In contrast the average content of dihydrotestosterone was almost 5 times higher in the hy- pertrophic glands $(0.60 \pm$ SEM $0.10 \mu \mathrm{g} / 100 \mathrm{~g})$ than in the normal prostates $(0.13 \pm$ SEM $0.05 \mu \mathrm{g} / 100 \mathrm{~g})$. There are of course many problems inherent in the comparison of surgical and autopsy material. The autopsy material was all taken from accident victims, and the average time between death and freezing of the glands was 11.5 hr. However, as indicated in Table I, incubation of a surgical specimen for a similar period of time resulted in no significant change in the concentration of testosterone and dihydrotestosterone. In addition, it is noteworthy that the concentrations of testosterone and androstenedione are identical in the autopsy and surgical specimens. For these reasons it has been concluded that the increased dihydrotestosterone content observed in the hypertrophic prostate probably represents a valid difference between the two groups of glands.

The data for testosterone and dihydrotestosterone in Table III have been plotted as a function of prostatic 


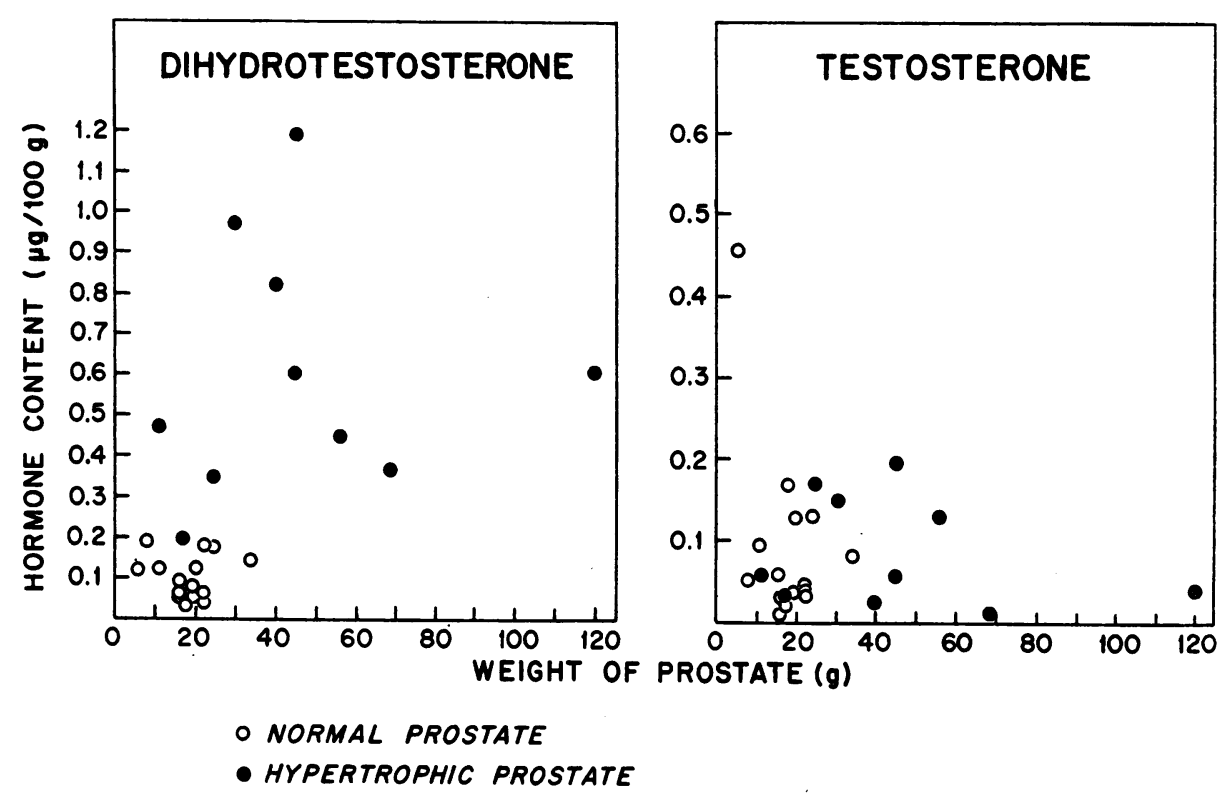

FIGURE 1 The relation between prostatic testosterone and dihydrotestosterone content and prostatic weight. The data in Table III have been plotted as a function of prostate weight.

weight (Fig. 1) and the age of the individual (Fig. 2). There is no striking correlation between the weight of the prostate and the concentration either of testosterone or of dihydrotestosterone in the prostate. Although there is no relation between patient age and the content of prostatic testosterone, the rise in prostatic dihydrotestosterone above the age of 60 is very striking.. It is clearly possible that the rise in the prostatic content of dihydrotestosterone might be a function of age per se rather than of prostatic hypertrophy.

Since human prostatic hypertrophy commonly begins in the periurethral region as a concentric process, the next study that was performed was a comparison of the hormone content in the periurethral and the outer gland-

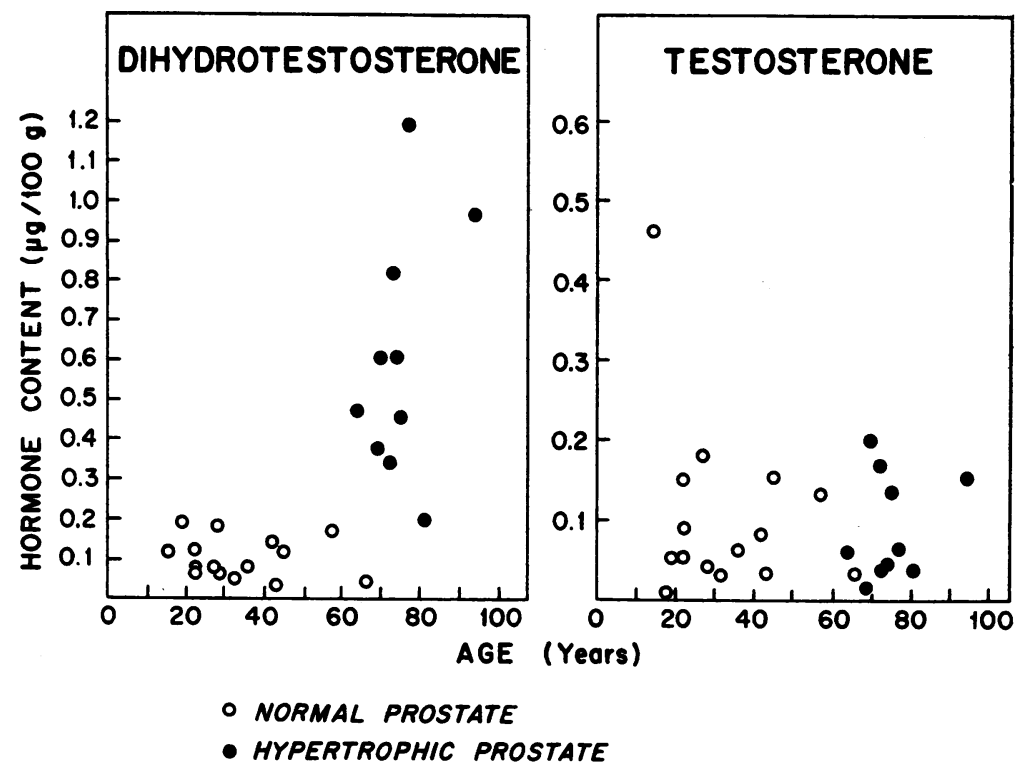

FIGURE 2 The relation between testosterone and dihydrotestosterone content in the prostate and age. The data in Table III have been plotted as a function of the age of the subjects. 


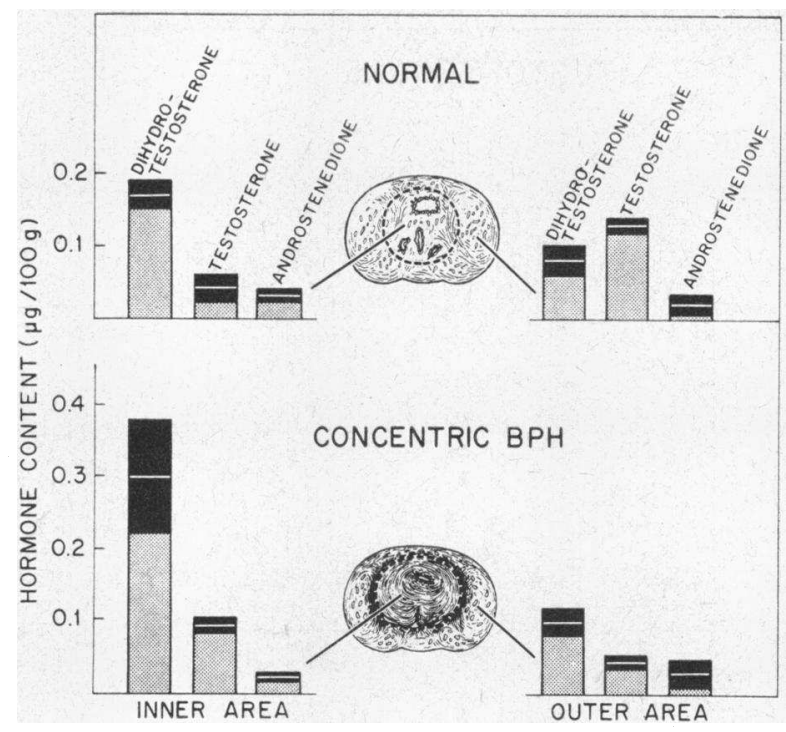

FIGURE 3 Androgen content of the inner and outer regions of normal and early hypertrophic prostates. Three normal prostates and four prostates with concentric hypertrophy were dissected into inner and outer regions as indicated by the dotted lines. The bar graphs represent the mean content in each area of testosterone, dihydrotestosterone, and androstenedione ( \pm SEM as a solid black portion of the bar above and below the mean values).

ular regions of normal and early hypertrophic glands (Fig. 3). In this study three normal glands (prostate weight averaged $17 \mathrm{~g}$, and the age of the patient averaged $52 \mathrm{yr}$ ) and four glands with concentric hypertrophy (patient age averaged $62 \mathrm{yr}$, and prostate weight averaged $32 \mathrm{~g}$ ) obtained at autopsy were dissected either into inner and outer areas or hyperplastic and normal regions, and the androgen content was measured as before. In the normal glands androstenedione content was similar in the two areas $(0.06 \pm 0.01$ and $0.04 \pm 0.02$ $\mu \mathrm{g} / 100 \mathrm{~g})$. The average concentration of testosterone was greater in the outer than the inner region $(0.13$ \pm 0.01 vs. $0.04 \pm 0.02 \mu \mathrm{g} / 100 \mathrm{~g}$ ). In contrast dihydrotestosterone content was 2 -fold greater in the periurethral region than in the outer areas of the normal glands $(0.17$ \pm 0.02 and $0.08 \pm 0.02 \mu \mathrm{g} / 100 \mathrm{~g}$ ). In the early hypertrophic glands the content of dihydrotestosterone was even higher in the periurethral area $(0.30 \pm 0.08 \mu \mathrm{g} / 100$ $\mathrm{g})$, and the testosterone content was slightly lower in the outer (normal) region $(0.05 \pm 0.01 \mu \mathrm{g} / 100 \mathrm{~g})$, but the other values were similar. The finding of a higher dihydrotestosterone content in the periurethral region than in the outer zones in both normal and early benign hypertrophic prostate glands is again compatible with a possible role for this metabolite in the pathogenesis of prostatic hypertrophy. It is also of interest in this regard that the average content of dihydrotestosterone in the entire gland in these early hypertrophic prostates
$(0.20 \mu \mathrm{g} / 100 \mathrm{~g})$ falls in between the values reported in Table III for normal and hypertrophic prostates.

Dihydrotestosterone formation in the prostate. In order to determine whether the increased concentration of dihydrotestosterone in the hypertrophic prostate might be due to an increased rate of dihydrotestosterone formation, the conversion of testosterone-1,2- ${ }^{3} \mathrm{H}$ to dihydrotestosterone- ${ }^{3} \mathrm{H}$ was then studied in tissue slice preparations from normal and hypertrophic prostate. In this system dihydrotestosterone formation was linear between tissue weights of 5 and $20 \mathrm{mg}$ and tended to plateau thereafter. In all routine studies tissue weights of $15 \mathrm{mg}$ or less were utilized. The relation between the concentration of testosterone in the incubation media and the rate of dihydrotestosterone formation was also investigated. At all concentrations studied between 0.7 and $7 \times 10^{-8} \mathrm{M}$, dihydrotestosterone formation was linear; since the rate of this reaction in prostate slices does not demonstrate saturation until the testosterone concentration exceeds the physiological range (21), the arbitrary value of $3.5 \times 10^{-8} \mathrm{M}$ testosterone was chosen for the subsequent studies since it corresponds to a value in the upper range of normal for the blood testosterone concentration of man, $1 \mu \mathrm{g} / 100 \mathrm{ml}(36,37)$.

The recovery of metabolites of testosterone with time after incubation with prostate slices is illustrated in Fig. 4. The concentration of dihydrotestosterone rose linearly for approximately $1 \frac{1}{2} \mathrm{hr}$ and somewhat more slowly thereafter; identity of this metabolite has been confirmed by gas-liquid chromatography and by crystallization with carrier to constant specific activity (21). Small amounts of other metabolites which have been tentatively identified as androstenedione, androstandione, and androstandiol were also formed as indicated in Fig. 4. For the routine assay used in all subsequent studies,

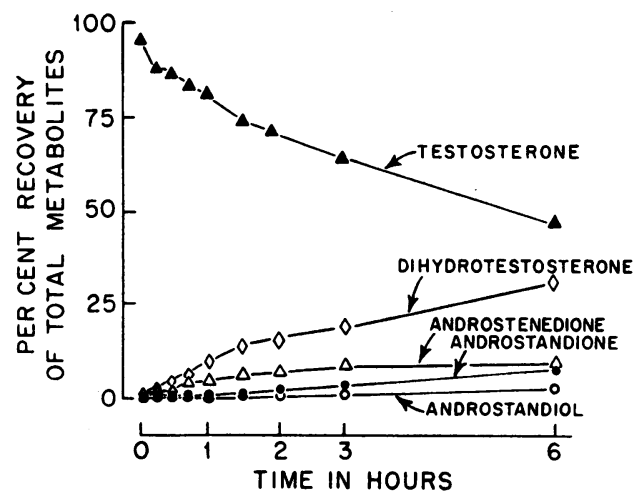

FIgURe 4 Formation of testosterone metabolites by prostate slices as a function of time. Slices of hypertrophic prostate (15 mg) were incubated with testosterone-1,2- ${ }^{8} \mathrm{H}$ (3.5 $\left.\times 10^{-8} \mathrm{M}\right)$, glucose $\left(1.1 \times 10^{-2} \mathrm{M}\right)$, and Krebs-Ringer phosphate buffer, $\mathrm{pH} 7.4$ at $37^{\circ} \mathrm{C}$ for varying periods. At the end of the incubation the samples were processed as described in the text. 
TABLE IV

Dihydrotestosterone Formation in Tissue Slices from Various Anatomical Sites of Hypertrophic Prostates

\begin{tabular}{|c|c|c|c|c|c|c|c|c|c|c|}
\hline \multirow[b]{2}{*}{ Anatomical site } & \multicolumn{9}{|c|}{ Dihydrotestosterone formation } & \multirow[b]{2}{*}{ Mean \pm SE } \\
\hline & 1 & 2 & 3 & 4 & 5 & 6 & 7 & 8 & 9 & \\
\hline \multicolumn{11}{|c|}{ 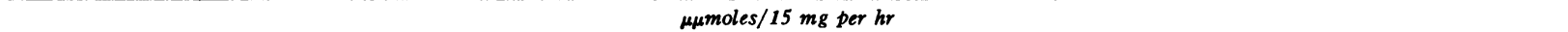 } \\
\hline Left lobe & 4.6 & 6.8 & 7.2 & 6.0 & 5.3 & 11.1 & 7.1 & 7.5 & 10.0 & $7.3 \pm 0.7$ \\
\hline Right lobe & 8.4 & 6.0 & 6.8 & 8.8 & 5.5 & 5.9 & 8.0 & 7.4 & 9.2 & $7.3 \pm 0.5$ \\
\hline Middle lobe & 7.0 & 7.4 & 5.6 & 9.8 & 6.7 & 7.5 & 7.3 & 7.0 & 14.6 & $8.1 \pm 0.9$ \\
\hline Surgical capsule & 4.2 & 5.6 & 4.9 & 5.1 & 7.0 & 7.0 & 3.2 & 5.4 & 4.7 & $5.4 \pm 0.5$ \\
\hline Mean $\pm S E$ & $6.0 \pm 1.0$ & $6.4 \pm 0.4$ & $6.1 \pm 0.5$ & $7.4 \pm 1.1$ & $6.5 \pm 0.7$ & $7.9 \pm 1.1$ & $6.4 \pm 1.1$ & $6.8 \pm 0.5$ & $9.6 \pm 2.0$ & \\
\hline
\end{tabular}

$15 \mathrm{mg}$ of prostate slices were incubated with testosterone-1,2- ${ }^{8} \mathrm{H}\left(3.5 \times 10^{-8} \mathrm{M}\right)$, glucose $\left(1.1 \times 10^{-2} \mathrm{M}\right)$, and Krebs-Ringer phosphate buffer, $\mathrm{pH} 7.4$ in a total volume of $2.5 \mathrm{ml}$ for $1 \mathrm{hr}$. All results have been expressed as micromicromoles of dihydrotestosterone formation per 15 milligrams of tissue per hour.

Next it was necessary to determine whether results from measurements in a single, small sample of tissue, as might be obtained at needle biopsy of the prostate, would provide a representative sampling of the rate of dihydrotestosterone formation by the entire gland. Therefore, dihydrotestosterone formation was measured in tissue slices obtained from different anatomical areas of nine hypertrophic prostates removed at surgery ( $\mathrm{Ta}$ ble IV). The individual results have been listed in regard to the site from which the slices were taken, and mean values have been given for each prostate tissue and each anatomical site tested. These data were subjected to an analysis of variance assuming that the locations are independent and the subjects heterogeneous, utilizing a randomized complete block system for assessment of variation among locations and individual glands. Provided that the surgical capsule was excluded there was no significant variation among lobes, and consequently all subsequent studies of dihydrotestosterone formation utilized slices of hypertrophic prostate which did not include the surgical capsule. It was concluded that stud-

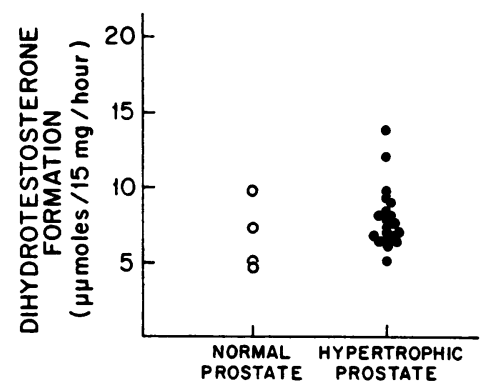

FIGURE 5 Dihydrotestosterone formation by slices of 4 normal and 20 hypertrophic prostate glands. The incubation conditions are described as the standard incubation in the text. ies utilizing a single, small specimen of prostate yield a representative assessment of dihydrotestosterone formation in the entire gland.

The results of measurements of dihydrotestosterone formation in slices of 4 normal and 20 hypertrophic prostates are given in Fig. 5. The average value for the four normal glands was $6.0 \pm \mathrm{SEM} 0.8 \mu \mu \mathrm{moles} / 15 \mathrm{mg}$ of tissue per hr, and in the hypertrophic glands the rate of dihydrotestosterone formation was not significantly different, $7.8 \pm$ SEM $0.5 \mu \mu$ moles $/ 15 \mathrm{mg}$ of tissue per $\mathrm{hr}$. The relation between prostatic weight and these values has been plotted in Fig. 6. For this formulation, the weight of the normal gland has been arbitarily calculated from the nomogram of Swyer (9) for the age of the individual. It is clear that even in prostate glands up to $125 \mathrm{~g}$ in weight there is no apparent change in the rate of dihydrotestosterone formation. While there are definite limitations to the interpretation of in vitro studies and particularly when the studies have been performed only in the presence of one substrate concentration, it is clear that no differences have been demonstrable in the rate of dihydrotestosterone formation from testosterone at a substrate concentration which approximates the physiological level. Nevertheless, the hypertrophic prostate with its average twofold increase in size has a

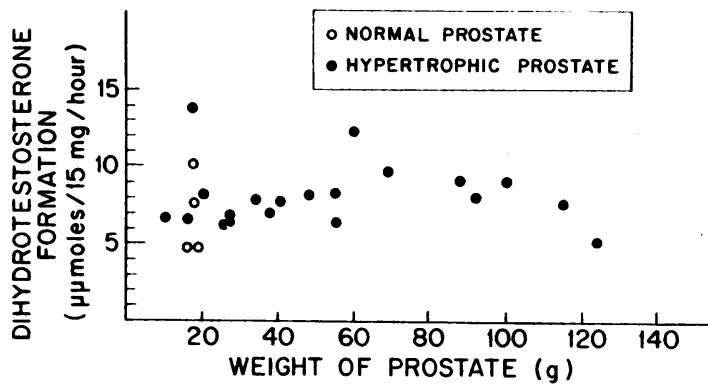

FIGURE 6 The relation between dihydrotestosterone formation by prostate slices and the weight of the prostate gland. The data in Fig. 5 have been plotted in relation to the weight of the prostate gland. The weight of the normal prostate was estimated from the nomogram of Swyer (9), and the hypertrophic prostates were measured directly. 
greater total capacity for dihydrotestosterone formation than does the normal gland.

\section{DISCUSSION}

As a result of the present studies it has been demonstrated that although the concentrations of testosterone and androstenedione do not differ between the normal and hypertrophic prostate glands, there is on an average a fivefold increase in the concentration of dihydrotestosterone in the hypertrophic as compared to the normal glands. Furthermore, in contrast to the other hormones, the concentrations of dihydrotestosterone in the periurethral areas of normal glands and early hypertrophic glands were two and threefold greater than the levels found in the outer regions of the glands, respectively. In view of the fact that the increased dihydrotestosterone content of the hypertrophic prostate correlates well with the age of the subject studied, it is not possible to conclude that dihydrotestosterone necessarily plays a role in the pathogenesis of benign prostatic hypertrophy in man. Indeed, on the basis of the studies reported here it is equally likely that the accumulation of dihydrotestosterone is a consequence of age per se or possibly even the result rather than the cause of benign prostatic hypertrophy.

Several types of evidence, however, do suggest that the accumulation of dihydrotestosterone may itself be causal in this condition. First, dihydrotestosterone formation correlates with prostatic size in 11 species of animals (21). Second, dihydrotestosterone is a potent stimulator of prostatic growth both in vitro and in vivo in the rat $(24,25,29)$. Third, early castration prevents the development of prostatic hypertrophy in man (10) and dog (4). Finally and most important, evidence has been obtained that not only does dihydrotestosterone also accumulate in canine prostatic hypertrophy but that dihydrotestosterone causes prostatic growth in the dog (30). Thus, the tentative hypothesis may be advanced that the accumulation of dihydrotestosterone in the human prostate may be causally related to the development of benign prostatic hypertrophy.

The results of the present studies do not furnish insight into the processes which lead to the accumulation of dihydrotestosterone in the hypertrophic prostate. Indeed, it has not been possible to demonstrate any difference in the conversion of testosterone to dihydrotestosterone between slices from normal and those from hypertrophic prostates. In this regard the situation is similar to the findings in canine prostatic hypertrophy, namely a fivefold higher than normal prostatic dihydrotestosterone content under circumstances in which dihydrotestosterone formation is apparently unchanged (30). This accumulation could be due to a number of processes. First, it is possible that the rate of dihydro- testosterone formation exceeds the rate of its destruction and turnover at all times; this seems unlikely since if this were the case dihydrotestosterone should accumulate gradually with age, whereas there is no change in its concentration until after the age of 65. Second, it is possible that dihydrotestosterone formation is increased in the hypertrophic prostate but that the techniques used here are not adequate to demonstrate such changes. Third, it is possible that dihydrotestosterone formation is selectively increased in periurethral tissue rather than in the gland as a whole, and the biopsy study was not designed properly to demonstrate such a difference. Fourth, the turnover or catabolism of dihydrotestosterone might diminish with aging. Finally, some pathway other than the direct reduction of testosterone within the gland might account for the accrual of dihydrotestosterone initially in the periurethral tissues and ultimately in the remainder of the prostate gland.

In conclusion, this study has demonstrated that dihydrotestosterone accumulation in the prostate occurs in benign prostatic hypertrophy in man. The problem of whether or not this dihydrotestosterone accumulation actually plays a role in the pathogenesis of benign prostatic hypertrophy in man and the mechanisms which lead to this accumulation await elucidation.

\section{ACKNOWLEDGMENTS}

Mary B. Neal has provided able assistance in the performance of these studies. In addition, we are grateful to Dr. Paul C. Peters and Dr. P. A. Duff and to the Urology staffs of the Parkland Memorial Hospital and the Dallas Veterans Administration Hospital for aid in the obtaining of surgical specimens.

This work has been supported by grants from the U. S. Public Health Service (AM 03892 and HD-00107) and the Robert A. Welch Foundation (I-181).

\section{REFERENCES}

1. Siiteri, P. K., and J. D. Wilson. 1970. Dihydrotestosterone (DHT) and benign prostatic hypertrophy (BPH) in man. Program of Endocrine Society. (Abstr. 78)

2. Moore, R. A. 1943. Benign hypertrophy of the prostate. A morphological study. J. Urol. 50: 680.

3. Moore, R. A. 1944. Benign hypertrophy and carcinoma of the prostate. Surgery. 16: 152.

4. Huggins, C. 1947. The etiology of benign prostatic hypertrophy. Bull. N. Y. Acad. Med. 23: 696.

5. Thomson, R. V., and J. E. Ash. 1954. Benign hyperplasia of the prostate gland. In Urology. M. Campbell, editor. W. B. Saunders Company, Phtiladelphia. 2: 1095.

6. Franks, L. M. 1954. Benign nodular hyperplasia of the prostate: a review. Ann. Roy. Coll. Surg. Engl. 14: 92.

7. Ofner, P. 1968. Effects and metabolism of hormones in normal and neoplastic prostate tissue. In Vitamins and Hormones. R. S. Harris, I. G. Wool, J. A. Loraine, and K. V. Thimann, editors. Academic Press, Inc., New York. 26: 237.

8. Teem, M. V. B. 1935. The relation of the interstitial cells of the testis to prostatic hypertrophy. J. Urol. 34: 692. 
9. Swyer, G. I. M. 1944. Post-natal growth changes in the human prostate. J. Anat. 78: 130.

10. Deming, C. L., and J. S. Wolf. 1939. The anatomical origin of benign prostatic enlargement. J. Urol. 42: 566.

11. Zuckerman, S. 1940. The histogenesis of tissues sensitive to oestrogens. Biol. Rev. (Cambridge). 15: 231.

12. Berg, O. A. 1958. Effect of stilboestrol on the prostate gland in normal puppies and adult dogs. Acta Endocrinol. 27: 155 .

13. Huggins, C., and R. A. Stevens. 1940. The effect of castration on benign hypertrophy of the prostate in man. J. Urol. 43: 705.

14. Scott, W. W., and J. C. Wade. 1969. Medical treatment of benign nodular prostatic hyperplasia with cyproterone acetate. J. Urol. 101 : 81.

15. Geller, J., R. Bora, T. Roberts, H. Newman, A. Lin, and R. Silva. 1965. Treatment of benign prostatic hypertrophy with hydroxyprogesterone caproate. Effect on clinical symptoms, morphology, and endocrine function. J. Amer. Med. Ass. 193: 121.

16. Farnsworth, W. E., and J. R. Brown. 1963. Testosterone metabolism in the prostate. In Biology of the Prostate and Related Tissues. E. P. Vollmer, editor. National Cancer Institute Monograph 12. 323.

17. Farnsworth, W. E., and J. R. Brown. 1963. Metabolism of testosterone by the human prostate. J. Amer. Med. Ass. 183: 436.

18. Shimazaki, J., H. Kurihara, Y. Ito, and K. Shida. 1965. Testosterone metabolism in prostate ; formation of androstan-17 $\beta$-ol-3-one and androst-4-ene,17-dione, and inhibitory effect of natural and synthetic estrogens. Gunma J. Med. Sci. 14: 313.

19. Shimazaki, J., H. Kurihara, Y. Ito, and K. Shida. 1965. Metabolism of testosterone in prostate. Gunma J. Med. Sci. $14: 326$.

20. Chamberlain, J., N. Jagarinec, and P. Ofner. 1966. Catabolism of $\left[4-{ }^{14} \mathrm{C}\right]$ testosterone by subcellular fractions of human prostate. Biochem. J. 99: 610 .

21. Gloyna, R. E., and J. D. Wilson. 1969. A comparative study of the conversion of testosterone to $17 \beta$-hydroxy$5 \alpha$-androstan-3-one (dihydrotestosterone) by prostate and epididymis. J. Clin. Endocrinol. Metab. 29: 970.

22. Bruchovsky, N., and J. D. Wilson. 1968. The conversion of testosterone to $5 \alpha$-androstan-17 $\beta$-ol-3-one by rat prostate in vivo and in vitro. J. Biol. Chem. 243: 2012.

23. Bruchovsky, N., and J. D. Wilson. 1968. The intranuclear binding of testosterone and $5 \alpha$-androstan-17 $\beta$-ol3-one by rat prostate. J. Biol. Chem. 243: 5953.

24. Baulieu, E. E., I. Lasnitzki, and P. Robel. 1968. Metabolism of testosterone and action of metabolites on pros- tate glands grown in organ culture. Nature (London). 219: 1155 .

25. Baulieu, E. E., I. Lasnitzki, and P. Robel. 1968. Testosterone, prostate gland and hormone action. Biochem. Biophys. Res. Commun. $32: 575$.

26. Dorfman, R. I., and R. A. Shipley. 1956. Androgens: Biochemistry, Physiology, and Clinical Significance. John Wiley \& Sons, Inc., New York. 118.

27. Saunders, F. J. 1963. Some aspects of relation of structure of steroids to their prostate-stimulating effects. In Biology of the Prostate and Related Tissues. E. P. Vollmer, editor. National Cancer Institute Monograph 12. 139.

28. Hilgar, A. G., and D. J. Hummel. 1964. Endocrine bioassay data. III. The androgenic and myogenic evaluation of steroids and other compounds. Assay I. Endocrine Evaluation Branch, CCNSC. In Androgenic and Myogenic Endocrine Bioassay Data. A. G. Hilgar and D. J. Hummel, editors. National Cancer Institute, Bethesda, Md. 15.

29. Wilson, J. D., and R. E. Gloyna. The intranuclear metabolism of testosterone in the accessory organs of reproduction. Recent Progr. Horm. Res. In press.

30. Gloyna, R. E., P. K. Siiteri, and J. D. Wilson. 1970. Dihydrotestosterone in prostatic hypertrophy. II. The formation and content of dihydrotestosterone in the hypertrophic canine prostate and the effect of dihydrotestosterone on prostate growth in the dog. J. Clin. Invest. 49: 1746.

31. Siiteri, P. K., P. Tippit, C. Yates, Jr., and J. C. Porter. 1968. A double isotope procedure for the determination of progestins in rat ovarian vein blood. Endocrinology. 82: 837.

32. Siiteri, P. K. 1969. Steroid analysis by the use of isotopic methods. Int. Congr. Ser. Exerpta Med. Found. 184: 476.

33. Folch, J., M. Lees, and G. H. Sloane Stanley. 1957. A simple method for the isolation and purification of total lipides from animal tissues. J. Biol. Chem. 226: 497.

34. Gomez, E. C., and S. L. Hsia. 1968. In vitro metabolism of testosterone-4- ${ }^{11} \mathrm{C}$ and $\Delta^{4}$-androstene-3,17-dione-4- ${ }^{14} \mathrm{C}$ in human skin. Biochemistry. 7: 24.

35. Wilson, J. D., and J. D. Walker. 1969. The conversion of testosterone to $5 \alpha$-androstan-17 $\beta$-ol-3-one (dihydrotestosterone) by skin slices of man. J. Clin. Invest. 48: 371 .

36. Rivarola, M. A., and C. J. Migeon. 1966. Determination of testosterone and androst-4-ene-3,17-dione concentration in human plasma. Steroids. 7: 103 .

37. Federman, D. D. 1967. Abnormal Sexual Development; A Genetic Endocrine Approach to Differential Diagnosis. W. B. Saunders Company, Philadelphia. 31. 